\title{
CT imaging is invaluable in diagnosing emphysematous pyelonephritis (EPN): a rare urological emergency
}

\author{
Ali Moostapha Tasleem, ${ }^{1}$ Paul Murray, ${ }^{2}$ Faqar Anjum, ${ }^{1}$ Seshadri Sriprasad ${ }^{1}$
}

${ }^{1}$ Department of Urology, Darent Valley Hospital, Kent, UK

${ }^{2}$ Darent Valley Hospital, Kent, UK

Correspondence to Ali Moostapha Tasleem, amt03@doctors.org.uk

Accepted 16 March 2014

\section{DESCRIPTION}

Emphysematous pyelonephritis (EPN) is an acute, fulminant and potentially fatal necrotising process with varying clinical presentations and a radiological classification. Most cases occur in diabetics with poor glycaemic control, while a minority are due to urinary tract obstruction. Early CT imaging is vital in diagnosing highly morbid EPN, with mortality rates of up to $69 \%$ described, and can necessitate nephrectomy. ${ }^{12}$

A 79-year-old woman, with non-insulin-dependent diabetes mellitus presented with confusion, fever, rigours and diffuse abdominal pain. Laboratory tests revealed a neutrophilia predominant leucocytosis,

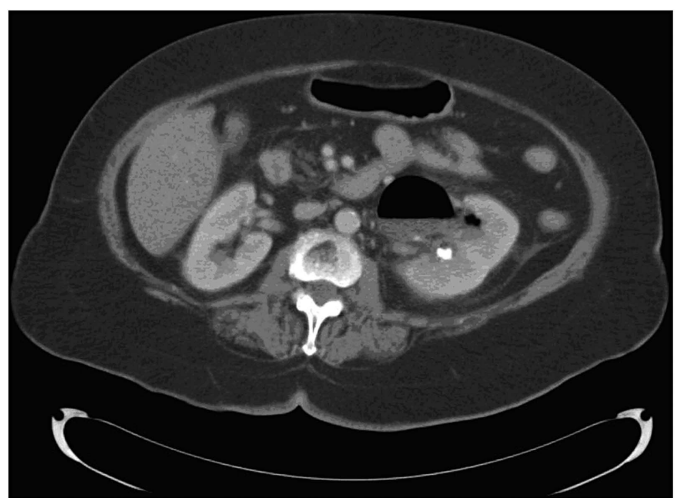

Figure 1 Axial CT section showing gas within the collecting system of the left kidney and perinephric stranding.

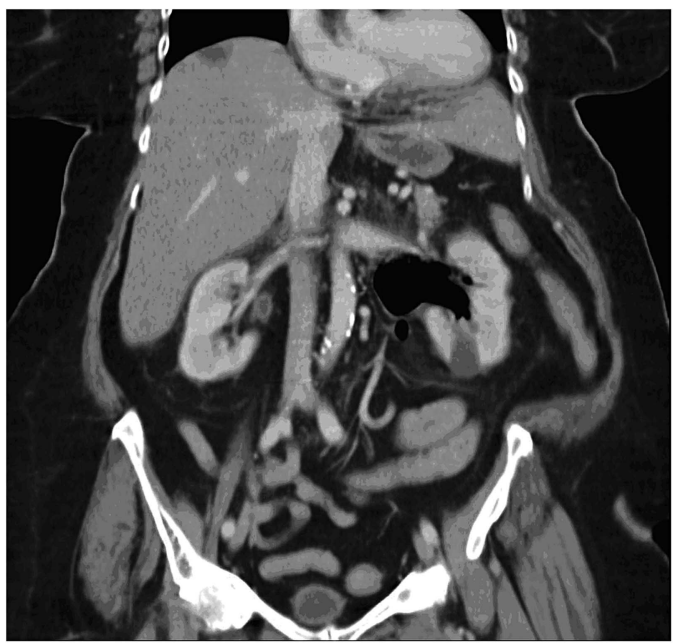

Figure 2 Sagittal CT section displaying an impressive volume of gas and resulting air-fluid level in the left kidney.

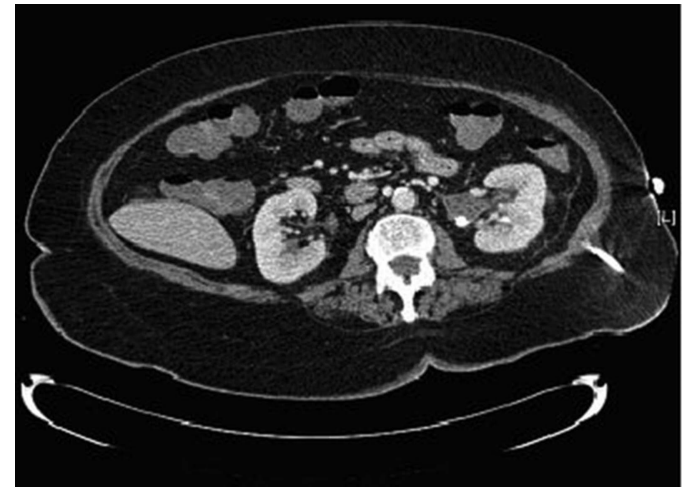

Figure 3 Sagittal CT section showing resolution of the gas within the renal collecting system and a decrease in inflammation. This corresponded to an improvement in the patient's clinical state.

normal renal function and metabolic acidosis on arterial analysis. Prompt contrast-enhanced CT imaging clinched the diagnosis of left type I EPN, revealing an obstructing ureteric calculus and demonstrating air-fluid levels with an impressive volume of gas in the collecting system (figures 1 and 2). Vigorous resuscitation, inotropic support and the insertion of an ultrasound-guided nephrostomy with broad-spectrum antibiotics given initially formed the cornerstone of management. Urine and blood cultures returned positive for Escherichia coli and intravenous amikacin was administered for 10 days. She remained an inpatient for 4 weeks requiring a programme of supplementary nasogastric feeding and a structured rehabilitation programme of intensive physiotherapy. She gradually improved clinically and follow-up CT imaging displayed resolution of the gas and a decrease in the associated perinephric stranding and infection (figure 3).

\section{Learning points}

- Suspect emphysematous pyelonephritis (EPN) in unwell elderly patients with diabetes with a fever of unknown origin, or whose clinical presentation is suggestive of a urinary tract infection.

- Prompt CT imaging is vital in establishing a diagnosis of EPN and ruling out other causes for intra-abdominal sepsis.

- Early and aggressive resuscitation, empirical antimicrobial therapy and a drainage nephrostomy tube are imperative for a positive clinical outcome. 
Our case demonstrates the high index of clinical suspicion required to diagnose EPN and aggressive subsequent treatment strategies. We advocate a multidisciplinary approach with prompt CT imaging, which is instrumental in categorising the severity and type of EPN, thus guiding management. ${ }^{3}$

Acknowledgements The authors would like to thank the medical records department.

Competing interests None.

Patient consent Obtained.
Provenance and peer review Not commissioned; externally peer reviewed.

\section{REFERENCES}

1 Saxena D, Aggarwal L, Tudu SK, et al. Emphysematous pyelonephritis-a rare surgical emergency presenting to the physician: a case report and literature review. Indian J Surg 2013;75 (Suppl 1):272-4.

2 Huang JJ, Tseng CC. Emphysematous pyelonephritis: clinicoradiological classification, management, prognosis, and pathogenesis. Arch Intern Med 2000;160:797-805.

3 Pontin AR, Barnes RD. Current management of emphysematous pyelonephritis. Nat Rev Urol 2009:6:272-9.

Copyright 2014 BMJ Publishing Group. All rights reserved. For permission to reuse any of this content visit http://group.bmj.com/group/rights-licensing/permissions.

BMJ Case Report Fellows may re-use this article for personal use and teaching without any further permission.

Become a Fellow of BMJ Case Reports today and you can:

- Submit as many cases as you like

- Enjoy fast sympathetic peer review and rapid publication of accepted articles

- Access all the published articles

- Re-use any of the published material for personal use and teaching without further permission

For information on Institutional Fellowships contact consortiasales@bmjgroup.com

Visit casereports.bmj.com for more articles like this and to become a Fellow 